Atmos. Chem. Phys., 10, 9225-9236, 2010

www.atmos-chem-phys.net/10/9225/2010/

doi:10.5194/acp-10-9225-2010

(C) Author(s) 2010. CC Attribution 3.0 License.

\title{
A global climatology of the mesospheric sodium layer from GOMOS data during the 2002-2008 period
}

\author{
D. Fussen ${ }^{1}$, F. Vanhellemont ${ }^{1}$, C. Tétard ${ }^{1}$, N. Mateshvili ${ }^{1}$, E. Dekemper ${ }^{1}$, N. Loodts ${ }^{1}$, C. Bingen ${ }^{1}$, E. Kyrölä ${ }^{2}$, \\ J. Tamminen ${ }^{2}$, V. Sofieva ${ }^{2}$, A. Hauchecorne ${ }^{3}$, F. Dalaudier ${ }^{3}$, J.-L. Bertaux ${ }^{3}$, G. Barrot ${ }^{4}$, L. Blanot ${ }^{4}$, O. Fanton \\ d'Andon $^{4}$, T. Fehr' ${ }^{5}$, L. Saavedra ${ }^{5}$, T. Yuan ${ }^{6}$, and C.-Y. She ${ }^{6}$ \\ ${ }^{1}$ Institut d'Aéronomie Spatiale de Belgique (BIRA-IASB), Brussels, Belgium \\ ${ }^{2}$ Earth observation, Finnish Meteorological Institute, Helsinki, Finland \\ ${ }^{3}$ LATMOS, Université Versailles Saint-Quentin, CNRS/INSU, Verrières-le-Buisson, France \\ ${ }^{4}$ ACRI-ST, Sophia-Antipolis, France \\ ${ }^{5}$ European Space Research Institute, European Space Agency, Frascati, Italy \\ ${ }^{6}$ Department of Physics, Colorado State University, Fort Collins, USA
}

Received: 13 December 2009 - Published in Atmos. Chem. Phys. Discuss.: 3 March 2010

Revised: 8 July 2010 - Accepted: 9 September 2010 - Published: 1 October 2010

\begin{abstract}
This paper presents a climatology of the mesospheric sodium layer built from the processing of 7 years of GOMOS data. With respect to preliminary results already published for the year 2003, a more careful analysis was applied to the averaging of occultations inside the climatological bins $\left(10^{\circ}\right.$ in latitude- 1 month). Also, the slant path absorption lines of the Na doublet around $589 \mathrm{~nm}$ shows evidence of partial saturation that was responsible for an underestimation of the Na concentration in our previous results. The sodium climatology has been validated with respect to the Fort Collins lidar measurements and, to a lesser extent, to the OSIRIS 2003-2004 data. Despite the important natural sodium variability, we have shown that the $\mathrm{Na}$ vertical column has a marked semi-annual oscillation at low latitudes that merges into an annual oscillation in the polar regions,a spatial distribution pattern that was unreported so far. The sodium layer seems to be clearly influenced by the mesospheric global circulation and the altitude of the layer shows clear signs of subsidence during polar winter. The climatology has been parameterized by time-latitude robust fits to al-
\end{abstract}

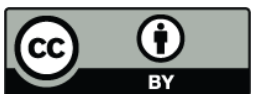

Correspondence to: D. Fussen (didier.fussen@oma.be) low for easy use. Taking into account the non-linearity of the transmittance due to partial saturation, an experimental approach is proposed to derive mesospheric temperatures from limb remote sounding measurements.

\section{Introduction}

The presence of layers of metal atoms in the mesosphere has been known for a long time and is believed to result from the ablation of meteoroids (see Plane et al., 2003 for a review). Sodium is probably the easiest species to measure, due to its abundance of about a few thousand atoms per cubic centimeter and because of a large resonant light absorption cross section. So far, the use of resonant lidars made possible the routine monitoring of the sodium mesospheric layer with high vertical and temporal resolutions (Arnold and She, 2003) whereas the geographical distribution of such measurements remains very sparse.

Amongst space borne spectrometers, the GOMOS instrument allowed the first global measurement of the sodium layer from 2003 data (Fussen et al., 2004) in occultation mode. Recently, 2003 and 2004 limb radiance observations

Published by Copernicus Publications on behalf of the European Geosciences Union. 
by the OSIRIS instrument have been processed (Gumbel et al., 2007) and the retrieved seasonal, latitudinal and vertical variations of the sodium concentration profile have been investigated (Fan et al., 2007).

GOMOS (Global Ozone Monitoring by Occultation of Stars) is a stellar occultation instrument on board the European Space Agency's Envisat satellite. As the satellite moves along its orbit, the selected star appears to set with respect to the Earth's atmosphere and the star spectral radiance is recorded with $0.5 \mathrm{~s}$ integration time and a vertical resolution better than $1.7 \mathrm{~km}$. GOMOS observes daily several hundred star occultations and it can measure in both day and night conditions, refered to as bright and dark limb measurements. The interested reader may find a general description of the instrument in this special issue or in Bertaux et al. (2004).

In brief, the atmospheric transmittance along the line of sight is derived by ratioing the observed spectrum and the exo-atmospheric reference. Knowing the absorption or scattering cross sections of the different atmospheric target molecules, their integrated concentration profiles (as a function of the tangent altitude of the line of sight ) can be separated in a process called spectral inversion. Afterwards, these profiles are vertically inverted to retrieve vertical concentration profiles of different molecules. The spectral ranges of the GOMOS spectrometers are 250-690 nm, 750-776 nm and $916-956 \mathrm{~nm}$, which allow for the retrieval of vertical profiles of $\mathrm{O}_{3}, \mathrm{NO}_{2}, \mathrm{NO}_{3}, \mathrm{H}_{2} \mathrm{O}, \mathrm{O}_{2}$ concentrations and aerosol extinction as operational GOMOS products. However, a careful statistical processing of the transmittance data reveals the clear spectral signature of the sodium $\mathrm{D}_{2}-\mathrm{D}_{1}$ doublet at $589.16 \mathrm{~nm}$ and $589.76 \mathrm{~nm}$ respectively.

This paper will present the results obtained from a general reprocessing of the 2002-2008 GOMOS data set that represents about 550000 star occultations. Firstly, we will discuss the statistical technique used to extract a significant signal in averaged transmittances, the vertical inversion algorithm and the details of the forward model used to retrieve the sodium concentration. Then, we will discuss different measurement cases, in presence or in absence of polar mesospheric clouds (PMCs) and our results will be intercompared with lidar data of Fort Collins and OSIRIS data. In the last section, we will present climatological results about the temporal, latitudinal and vertical variability of the mesospheric sodium layer.

\section{Methodology}

It is important to notice that the apparent (i.e. after convolution by the spectrometer spectral function) slant path optical thickness associated with the sodium extinction along the line of sight has a small value mostly not larger than about 0.005 , which corresponds to a vertical optical thickness in the $10^{-4}$ range. Therefore, it is excluded to apply the nominal GOMOS data processing model to the transmittance measured in individual occultations. Instead, it is necessary to properly average a large number of transmittances into monthly bins having a $10^{\circ}$ latitudinal extension in order to increase the signal-to-noise (SNR) ratio.

We have to draw attention on the following issues. Firstly, GOMOS measurements have a variable SNR because stars have different magnitudes and temperatures. Also, bright limb measurements turned out to be much noisier than dark limb occultations. A recent analysis of the GOMOS limb radiance extracted from the upper and lower bands of the CCD detector has shown that a significant level of straylight contaminates the bright limb measurements in the upper atmosphere. Finally, the CCD aging is responsible for a continuous increase of dark charge and the so-called "radiotelegraphic" signal can suddenly increase the dark charge level of a particular pixel during the occultation; furthermore, there are cases where cosmic ray events were not correctly removed during the level $1 \mathrm{~b}$ data processing.

In our preliminary paper (Fussen et al., 2004), not enough effort was done in computing the averaged transmittance of a given bin in a robust way, leading sometimes to contamination by outliers, in particular for bright limb cases having a small population of occultations. In order to improve the statistical significance of the averaged transmittance, we have used the median estimator instead of the mean, because the first is known to be much more robust against the presence of outliers. On the other way, as the signal-to-noise ratios of different measurements may differ considerably, it is useful to combine transmittances weighted with respect to their estimated measurement errors.

In a first step, for all wavelengths $\lambda_{j}$ and tangent altitudes $h_{i}$, the GOMOS transmittances $T_{i}\left(\lambda_{j}, h_{i}\right)$ with measurement error variances $s_{i}^{2}\left(\lambda_{j}, h_{i}\right)$ belonging to a particular bin are linearly interpolated on a common $1-\mathrm{km}$ tangent altitude grid after which the weighted median transmittance $T(\lambda, h)$ is computed (we will omit subscripts from here). In Fig. 1, we show how the sodium spectral signature is emerging when the number of binned occultations is increased.

The sodium absorption doublet $\mathrm{D}_{2}, \mathrm{D}_{1}$ corresponds to the fine-structure transitions $3^{2} \mathrm{~S}_{1 / 2}-3^{2} \mathrm{P}_{3 / 2}\left(\lambda_{\mathrm{D}_{2}}=589.16 \mathrm{~nm}\right)$ and $3^{2} \mathrm{~S}_{1 / 2}-3^{2} \mathrm{P}_{1 / 2}\left(\lambda_{\mathrm{D}_{1}}=589.76 \mathrm{~nm}\right)$ (Chamberlain, 1961; Steck, 2003) separated by a $0.6 \mathrm{~nm}$ interval that is partially resolved by GOMOS (around the considered wavelength range, the pixel sampling is about $0.31 \mathrm{~nm}$ and the spectrometer total line spread function has a $0.54 \mathrm{~nm}$ FWHM). Both transitions are split into two groups of hyperfine structure transitions respectively ( $\mathrm{D}_{2 \mathrm{a}}$ (3 lines), $\mathrm{D}_{2 \mathrm{~b}}$ (3 lines), $\mathrm{D}_{1 \mathrm{a}}$ (2 lines), $\mathrm{D}_{1 \mathrm{~b}}$ (2 lines)). The separation between $\mathrm{D}_{2 \mathrm{a}}-\mathrm{D}_{2 \mathrm{~b}}$ and $\mathrm{D}_{1 \mathrm{a}}-\mathrm{D}_{1 \mathrm{~b}}$ subgroups is about $0.002 \mathrm{~nm}$ and comparable to the Doppler broadening in the mesosphere. Hence, the spectral sounding of a hyperfine subgroup by a ground-based lidar allows the retrieval mesospheric temperatures at the altitude of the sodium layer (Fricke and von Zahn, 1985). This high resolution spectroscopy is of course not accessible to GOMOS and one may consider that each hyperfine subgroup is spread by the instrument line spread function. 


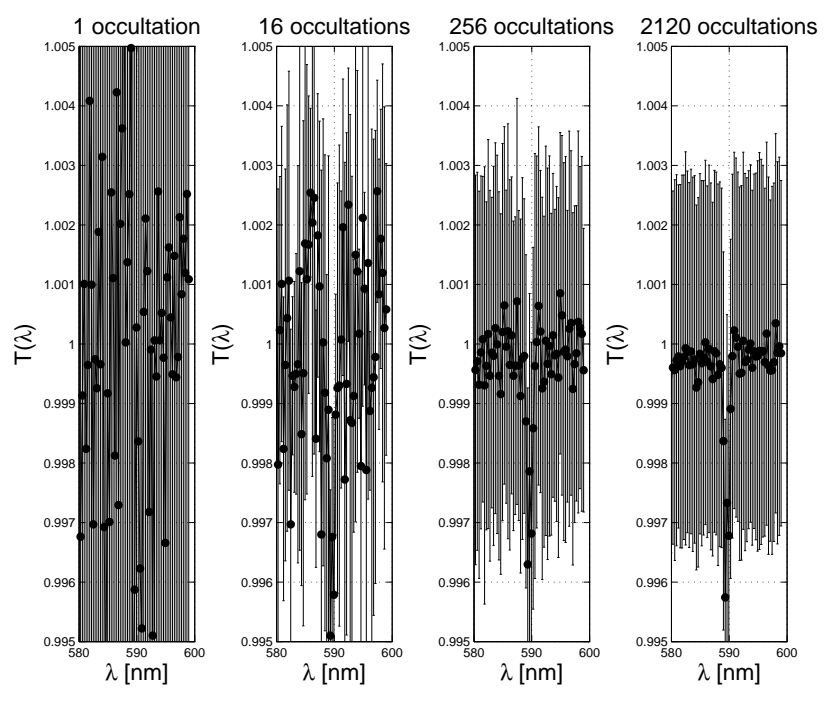

Fig. 1. GOMOS weighted median transmittance as a function of the number of occultations for the bin $70^{\circ} \mathrm{N}-80^{\circ} \mathrm{N}$ in January 2005.

A difficulty also arises with the stellar spectra that may contain Na Fraunhofer lines. The GOMOS instrument measures a mean transmittance convoluted by the instrumental spectral function and is therefore sensitive to the stellar irradiance depletion within the Fraunhofer line. However, the stellar spectrum is shifted by the Doppler effect as seen from a geocentric reference frame. For the whole data set used here, the median stellar radial velocity is about $18 \mathrm{~km} / \mathrm{s}$ equivalent to a Doppler shift of $0.036 \mathrm{~nm}$ that strongly reduces the overlap between the Fraunhofer line and the atmospheric absorption line. This condition is not always exactly true but difficult to assess accurately due to the scarcity of high resolution stellar spectra and also because the star radial velocity is changing considerably during a one month period. In an attempt to evaluate the impact of Fraunhofer depletion on the apparent slant optical tickness measured by GOMOS, we have used experimental and synthetic stellar spectra for the month January 2003 in the $70^{\circ} \mathrm{N}-80^{\circ} \mathrm{N}$ latitude bin, taking into account the star radial velocity for each individual occultation. Depending on the $\mathrm{D}_{2} / \mathrm{D}_{1}$ stellar ratio, we conclude that the underestimation of the apparent slant optical thickness lies between $17 \%$ and $25 \%$.

In our previous paper (Fussen et al., 2004), we used a simple approach for the retrieval of $N(h)$, the integrated mesospheric sodium concentration along the line-of-sight (or slant column). It was based on the description of the measured transmittance according to the Bouguer's law as it is usually done in lidar measurements (Fricke and von Zahn, 1985; Megie and Blamont, 1977).

$$
\begin{aligned}
T(\lambda, h) & =\exp (-\tau(\lambda, h))=\exp (-\sigma(\lambda) N(h)) \\
& \simeq 1-\sigma(\lambda) N(h)
\end{aligned}
$$

where the linearization is possible for small values of $\tau(\lambda, h)$ and allows to define an effective cross section $\sigma_{e}=2.12 \mathrm{E}-14 \mathrm{~cm}^{2}$ for the considered wavelength interval $(\Delta \lambda=1.25 \mathrm{~nm}=4$ GOMOS pixels) over which an averaged slant path optical thickness $\tau_{e}$ was retrieved:

$$
\begin{aligned}
\tau_{e}(h) & =\frac{1}{\Delta \lambda} \int \tau(\lambda, h) d \lambda=\frac{1}{\Delta \lambda} \int \sigma(\lambda) N(h) d \lambda \\
& =\sigma_{e} N(h)
\end{aligned}
$$

However, this simple description has been suspected to be responsible for the $30 \%$ difference with respect to validating data (Fussen et al., 2004). Coming back to the optical thickness $\tau_{\nu}$ (at the frequency $\nu$ ) of a line broadened by thermal motion, we may write:

$\tau_{\nu}=\tau_{0} \exp \left(-\left(\frac{c\left(\nu-v_{0}\right)}{U \nu_{0}}\right)^{2}\right)=\tau_{0} \exp \left(-x^{2}\right)$

where $c$ is the speed of light and $U=\sqrt{\frac{2 k t}{M}}$ stands for the most probable velocity of sodium atoms $(M=3.82 \mathrm{E}-26 \mathrm{~kg}, U \simeq$ $400 \mathrm{~m} / \mathrm{s}$ for a temperature of $t=220 \mathrm{~K}$ ). At the line center, the optical thickness $\tau_{0}$ for the slant column $N(h)$ reads

$\tau_{0}=N \frac{c}{U}\left(\frac{\pi e^{2}}{m_{e} c}\right) \frac{1}{v_{0} \sqrt{\pi}} f_{X}$

where $m_{e}, e, f_{X}$ refer respectively to electron mass, electron charge and oscillator strengh of the considered resonant optical transition $X$. More explicitely, we use the following spectroscopic data (Chamberlain, 1961; Steck, 2003): $\frac{\pi e^{2}}{m c^{2}}=0.02647 \mathrm{~cm}^{2} / \mathrm{s}, \quad f_{\mathrm{D}_{2}}=0.6405$ and $f_{\mathrm{D}_{1}}=$ $0.3199, f_{\mathrm{D}_{2 \mathrm{a}}}=\frac{5}{8} f_{\mathrm{D}_{2}}, f_{\mathrm{D}_{2 \mathrm{~b}}}=\frac{3}{8} f_{\mathrm{D}_{2}}, f_{\mathrm{D}_{1 \mathrm{a}}}=\frac{5}{8} f_{\mathrm{D}_{1}}, f_{\mathrm{D}_{1 \mathrm{~b}}}=$ $\frac{3}{8} f_{\mathrm{D}_{1}}, \quad \lambda_{\mathrm{D}_{2 \mathrm{a}}}=589.159067 \mathrm{~nm}, \quad \lambda_{\mathrm{D}_{2 \mathrm{~b}}}=589.157097 \mathrm{~nm}$, $\lambda_{\mathrm{D}_{1 \mathrm{a}}}=589.757462 \mathrm{~nm}, \lambda_{\mathrm{D}_{1 \mathrm{~b}}}=589.755332 \mathrm{~nm}$.

In Fig. 2, we present the complementary transmittance $(1-T)$ for the $\mathrm{D}_{1}$ transition for different slant columns. For a Gaussian altitude profile with a FWHM of $20 \mathrm{~km}$, a reference value for the sodium vertical column is $5 \mathrm{E} 9 \mathrm{~cm}^{-2}$ whereas the corresponding slant column is about 40 times larger (Fussen et al., 2004), i.e. $2 \mathrm{E} 11 \mathrm{~cm}^{-2}$. For the weak absorption regime, the complementary transmittance is close to the optical thickness and therefore proportional to the oscillator strength. When using the vertical column value we find a ratio $\mathrm{D}_{1 \mathrm{a}} / \mathrm{D}_{1 \mathrm{~b}}$ of 1.658 , close to the expected value of $5 / 3=1.667$ in the optically thin limit. For the corresponding slant column, we find a ratio of 1.424 , suggesting a significative deviation from the linear regime.

Integrating Eq. 3 in the frequency space over a $\Delta v$ interval, we may define an effective transmittance $\bar{T}$ and the associated effective cross section $\bar{\sigma}$ as:

$$
\bar{T}=\exp (-\bar{\sigma} N)=\frac{U \nu_{0}}{c \Delta v} \int \exp \left(-\tau_{0} \exp \left(-x^{2}\right)\right) d x
$$

The equation above indicates that the effective cross section $\bar{\sigma}$ is clearly a non-linear function of $N$ (due to Eq. 4) and the ratio $\varrho(N)=\bar{\sigma}(N) / \bar{\sigma}(0)$ goes to zero when the saturation of the transition increases (see Fig. 4). 


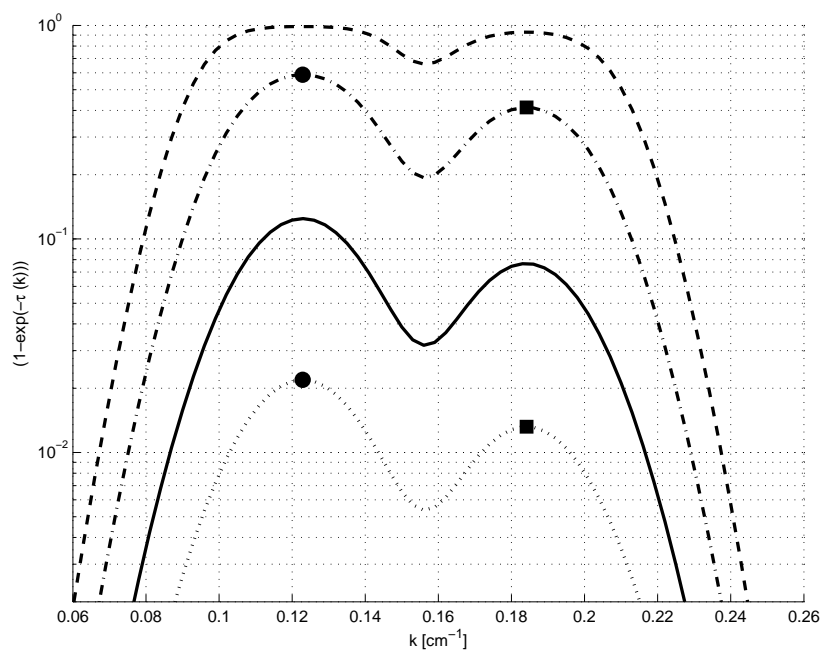

Fig. 2. Theoretical complementary transmittances for the $\mathrm{D}_{1 \mathrm{a}}$ and $\mathrm{D}_{1 \mathrm{~b}}$ sodium absorption lines as function of wavenumber difference (the zero of the wavenumber range is $16956 \mathrm{~cm}^{-1}$ ) for different columns; dotted line: $N=5 \mathrm{E} 9 \mathrm{~cm}^{-2}$; full line: $N=3 \mathrm{E} 10 \mathrm{~cm}^{-2}$; dashed-dotted line: $N=2 \mathrm{E} 11 \mathrm{~cm}^{-2}$; dashed line: $N=1 \mathrm{E} 12 \mathrm{~cm}^{-2}$; dots and squares refer to the maxima of the the $\mathrm{D}_{1 \mathrm{a}}$ and $\mathrm{D}_{1 \mathrm{~b}}$ absorptions for the sodium reference vertical and slant columns. In the weak absorption regime, the ratio $\mathrm{D}_{1 \mathrm{a}} / \mathrm{D}_{1 \mathrm{~b}}$ should be equal to $5 / 3$.

In Fig. 3, the doublet absorption features of the experimental transmittance were retrieved by fitting a double Gaussian shape

$$
\begin{aligned}
T(\lambda, h) & =1-a_{1}(h) \exp \left(-\left(\frac{\lambda-\left(a_{3}(h)+0.5984 \mathrm{~nm}\right)}{a_{4}(h)}\right)^{2}\right) \\
& -a_{2}(h) \exp \left(-\left(\frac{\lambda-a_{3}(h)}{a_{4}(h)}\right)^{2}\right)
\end{aligned}
$$

with identical width for both lobes $(0.5984 \mathrm{~nm}$ is the theoretical separation of the absorption doublet) and after having removed the baseline transmittance by using a low-order polynomial . This example is shown at a tangent altitude of $90 \mathrm{~km}$ for a latitudinal bin $70^{\circ}-80^{\circ}$ in which a large number of Sirius occultations with a high SNR ratio were available. The retrieved centroid of the $\mathrm{D}_{2}$ line is $589.29 \mathrm{~nm}$ with a FWHM width of $0.46 \mathrm{~nm}$ a number that is close to the pre-launch value of $0.54 \mathrm{~nm}$.

\section{Results and validation}

\subsection{Observation of polar mesospheric clouds (PMC)}

The sodium retrieval procedure described above has been applied to the full GOMOS data set. The intercomparison of the binned transmittances for different seasons and observation modes (dark limb/bright limb) shows very different situations. In Fig. 5, we focus on the polar regions

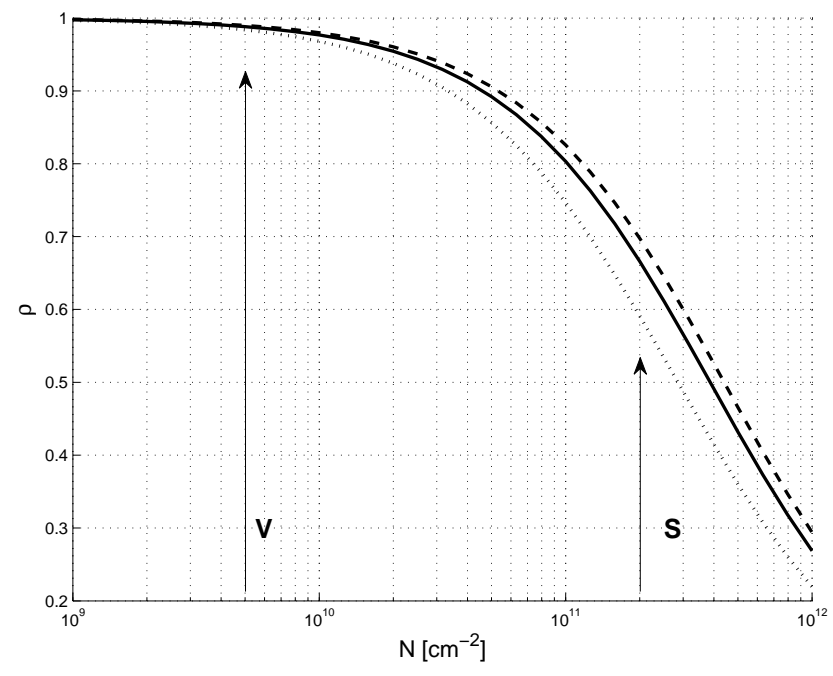

Fig. 3. Relative effective cross section as a function of sodium column for different temperatures; dotted line: $T=100 \mathrm{~K}$; full line: $T=200 \mathrm{~K}$; dashed line: $T=300 \mathrm{~K}$. The arrows refer to the reference values for the vertical column (V) and slant column (S).

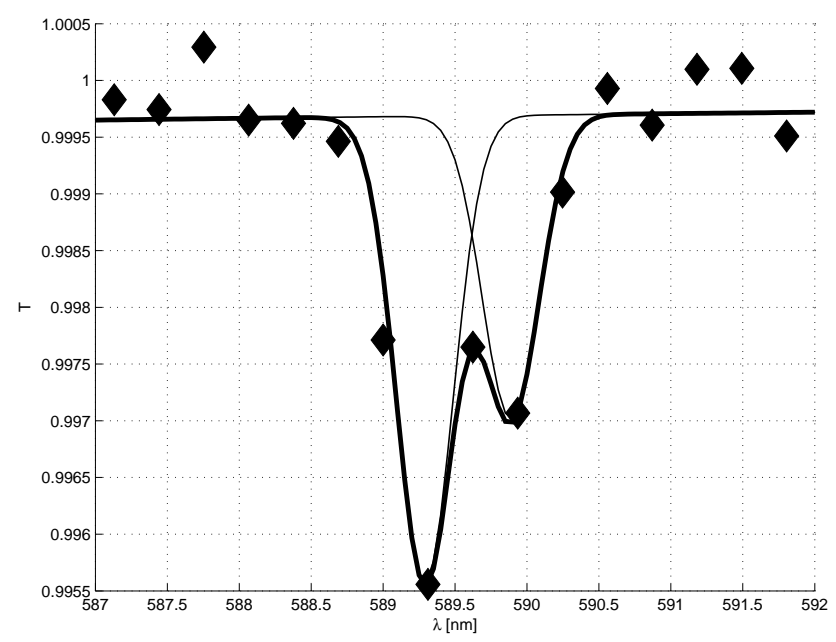

Fig. 4. Diamonds: the median transmittance (of 1121 occultations) measured between $70^{\circ} \mathrm{N}$ and $80^{\circ} \mathrm{N}$ during January 2003. Thin full lines: individual $\mathrm{D}_{2}$ and $\mathrm{D}_{1}$ absorptions assuming to have the same instrumental line spread function. Thick line: best fit for the total transmittance (with baseline removed).

$\left(70^{\circ}<\varphi<80^{\circ}\right)$ in both hemispheres at solstice time. Generally speaking, the summer solstice delivers less accurate data because most occultations contributing to the bin have been performed in bright limb mode which is strongly contaminated by straylight. In order to identify the signature of sodium absorption, we have plotted the transmittance at $589.3 \mathrm{~nm}$ (a pixel with significant absorption by the $\mathrm{D}_{2}$ line) and two control pixels with no specific absorption, respectively at 588.1 and $590.6 \mathrm{~nm}$. We also plotted the mean transmittance outside the absorption region in the interval 

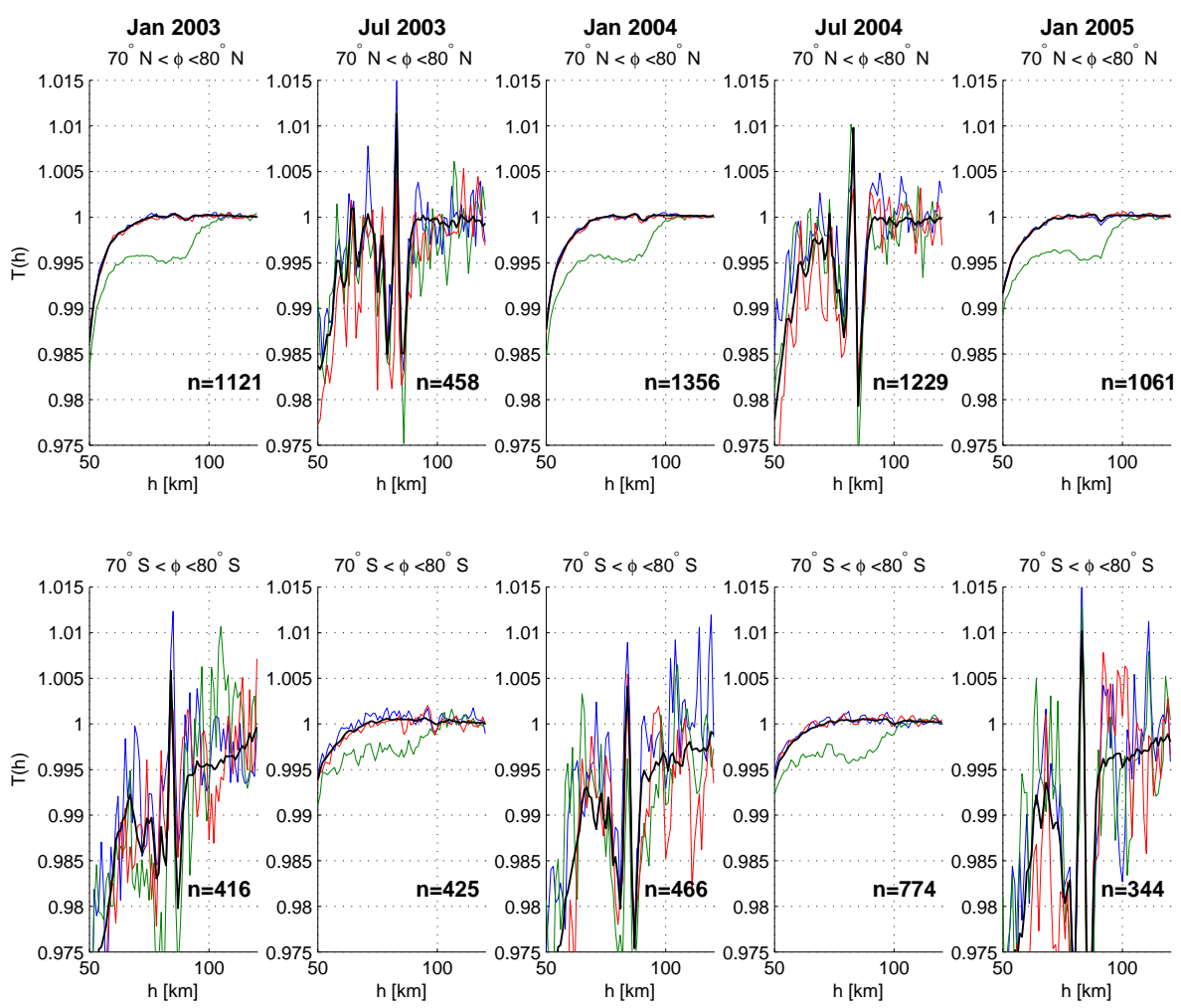

Fig. 5. Median transmittances as a function of tangent height for polar bins during the months January and July from 2003 till 2005 . The number of occultations in the bin is indicated by $n$. In each subplot, red and blue colors correspond to control pixels (with only a smooth ozone absorption) whereas the green color represents a pixel associated with the $\mathrm{D}_{2}$ sodium absorption that exhibits a depression due to the Na mesospheric layer. The black curve is the mean transmittance in a $20 \mathrm{~nm}$ window around the the Na absorption region. Close to summer solstices in each hemisphere, PMC dips and "flashes" are clearly seen around $83 \mathrm{~km}$, for all wavelengths.

$579.7-599 \mathrm{~nm}$ to filter out most of the residual noise. In the winter solstice cases, the sodium absorption is clearly visible whereas the control pixels and the mean window transmittance only show smooth and weak extinction due to ozone absorption in the Chappuis band and to Rayleigh scattering. The summer solstices exhibit a remarkable and reproducible feature in both hemispheres: around $83 \mathrm{~km}$, a sharp "emission" peak appears that affects all pixels of the spectral window. In view of the considered season and latitude, these peaks are attributed to the scattering of solar light by polar mesospheric clouds (PMC) into the GOMOS line-ofsight. Some supplementary scattering features are also visible at lower altitudes although less reproducible. It has been suggested by Plane et al. (2004), that the mesopheric metallic layers may act as nucleation seeds for the formation of PMC's, showing a strong anticorrelation in their respective abundances. Na absorption is still visible in presence of PMCs but these are very narrow layers with limited spatial extent and there is no guarantee that GOMOS is observing $\mathrm{Na}$ and PMC's in the same air mass. On the other hand, Gardner et al. (2005) showed that removal on PMCs is required to model the summertime $\mathrm{Fe}$ and $\mathrm{Na}$ layers over South Pole.

\subsection{Inversion and retrieval of sodium concentration profiles}

In the use of an optimal estimation method, the selected a priori information is crucial to avoid any bias in the retrieval. But so far, there does not exist a validated climatology of the global sodium distribution. Therefore we have preferred not to use an optimal estimation technique for retrieving the vertical profile of sodium concentration but instead to limit the number of retrieved parameters by imposing a generalized Gaussian distribution as:

$n(z)=n_{0} \exp \left(-\left|\frac{z-z_{p}}{\alpha}\right|^{\epsilon}\right)$

where $n_{0}$ is the peak concentration at altitude $z_{p}$. The sodium concentration peak extends over a region of typical size $\alpha$ whereas the exponent $\epsilon$ expresses the sharpness of the maximum concentration. The forward model contains then only four parameters to retrieve $\left(n_{0}, z_{p}, \alpha\right.$ and $\left.\epsilon\right)$ this small number being a trade-off between bins with a high SNR and bins that are poorly populated. For the same reason, it was decided to keep the mesospheric temperature fixed at a climatological value because a meaningful temperature retrieval would only make sense for the best bins. The modelled 

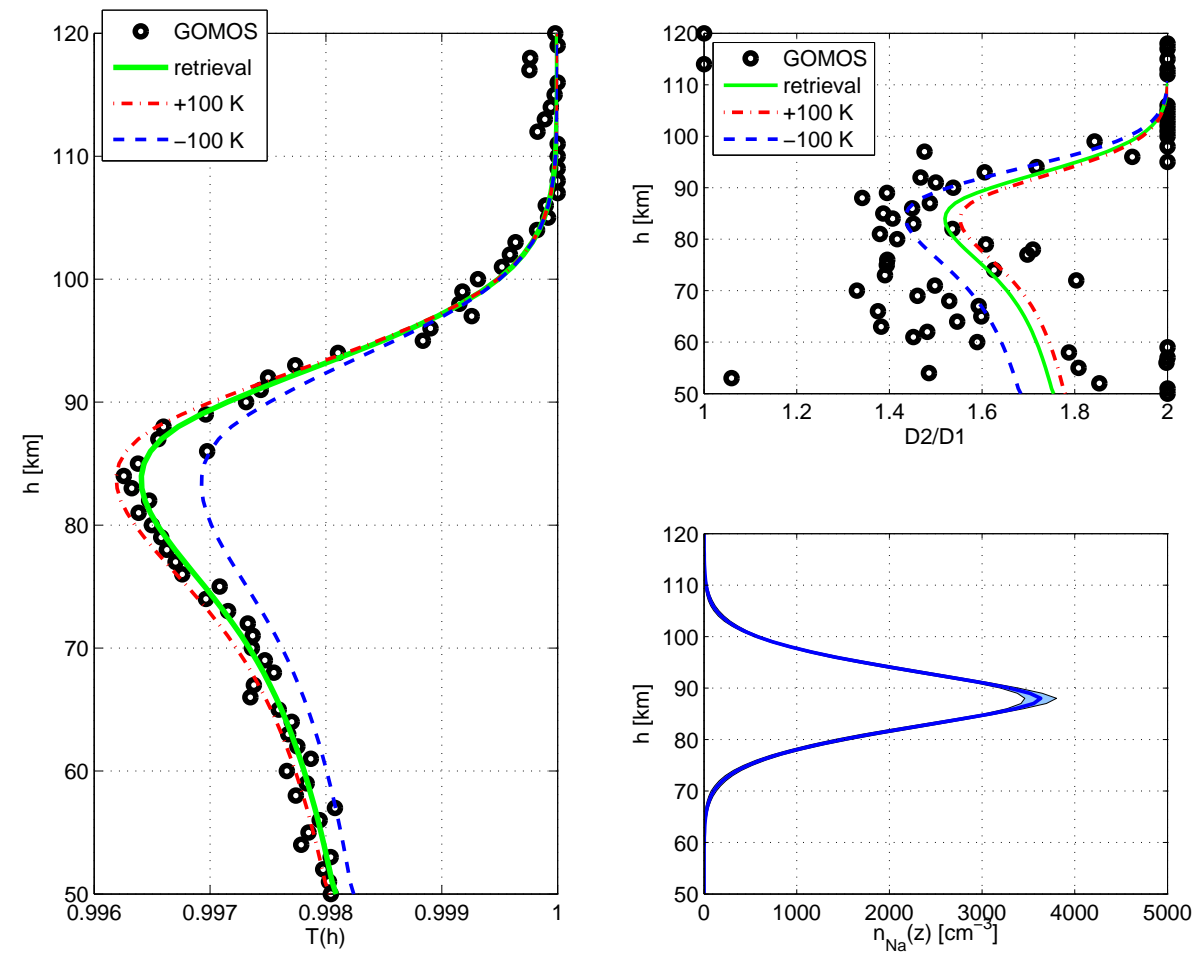

Fig. 6. Inversion of the measured effective transmittance profile for January 2003 in the latitudinal bin $70^{\circ} \mathrm{N}-80^{\circ} \mathrm{N}$. Left side: effective transmittance versus tangent height; circles: measured values; green full line: best modeled value; red and blue lines: same conditions as for green line but with $+100 \mathrm{~K}$ (respectively $-100 \mathrm{~K}$ ) added to the used climatological temperature profile. Right side: top: $\mathrm{D}_{2} / \mathrm{D}_{1}$ ratio for the same case; bottom: retrieved Na vertical profile with its error bar envelope.

transmittance is built from the spatial integration of highly resolved partial optical thicknesses along the optical path, followed by a spectral integration over the Maxwell-Boltzman distribution and finally reduced to an effective transmittance over the same wavelength interval on which equation 6 has been fitted. The inversion then proceeds through standard non-linear minimization techniques to retrieve $\left(n_{0}, z_{p}, \alpha\right.$ and $\epsilon)$ and the associated error budget.

In Fig. 6, we present the result of the inversion for January 2003 between $70^{\circ} \mathrm{N}$ and $80^{\circ} \mathrm{N}$. In the left panel, the green curve is the best effective transmittance matching the observed values as a function of the tangent height. Notice the typical asymmetric shape of the transmittance profile when the line-of-sight crosses a thin absorbing layer: a sharp edge at higher tangent heights (upper side of the layer) followed by a smoother dependence due to the Earth's curvature as the tangent height decreases. In the same panel, we have also plotted the transmittances that would be caused by the same sodium concentration profile with a homogeneous temperature bias of $\pm 100 \mathrm{~K}$ added to the climatological values. Clearly, a precision of 10 to $20 \mathrm{~K}$ in effective temperature retrieval would be difficult to achieve with respect to the available SNR. In the right part of the figure, the top panel represents the $D_{2} / D_{1}$ ratio obtained for the same case whereas the bottom panel shows the retrieved sodium profile and the associated error bar envelope.

\subsection{Validation}

As a first validation test of our results, we compared the sodium columns (i.e. the sodium concentration profiles integrated along the vertical) obtained from GOMOS and those published by She et al. (2000) from lidar data at Fort Collins (latitude $41^{\circ} \mathrm{N}$; notice that there is a typo error in Table 2 of this reference where the July abundance should be equal to about 2.05 instead of 1.20). The comparison is presented in Fig. 7 for 67 months of available GOMOS data (August 2002-June 2008) averaged (with weighting) between $30^{\circ} \mathrm{N}$ and $50^{\circ} \mathrm{N}$ and reported with their estimated error bars. The spread of the GOMOS data gives some indication of the quite important natural variability. The observed variability was confirmed by the same authors in a dedicated statistics computed for the period 2002-2006 and restricted to the lidar data obtained during the same local time periods of the GOMOS measurements. Both Fort Collins climatologies are consistent but not exactly identical. We have also computed a climatological GOMOS Na column by means of a fourth order polynomial with weighting and periodicity constraints. There is a fair agreement between GOMOS and Fort Collins data sets, taking into account the GOMOS error bars and the interannual variability. The seasonal modulation is however a little bit less contrasted for the GOMOS data than for the Fort Collins values. 


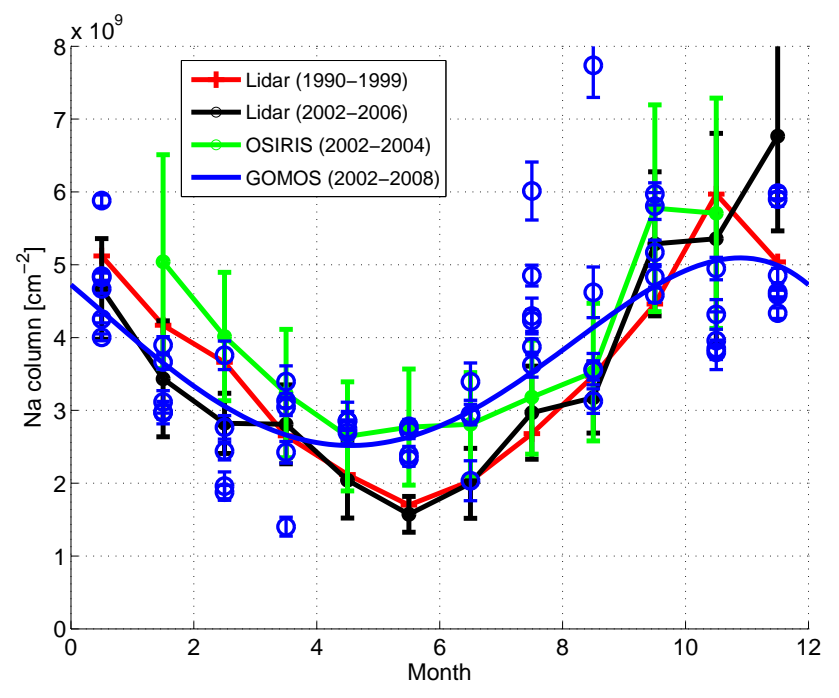

Fig. 7. Intercomparison of $\mathrm{Na}$ column climatologies measured in the $30^{\circ}-50^{\circ}$ latitude band. Blue circles: GOMOS data (20022008) and associated error bars; blue line: least-squares polynomial fit for all GOMOS data; red line: Fort Collins $\left(41^{\circ} \mathrm{N}\right)$ lidar climatology (1990-1999); black line: Fort Collins lidar climatology (2002-2006) restricted to local time periods corresponding to GOMOS observations; green line: OSIRIS measurements (2003-2004) from Gumbel et al. (2007).

We have also intercompared our data with recent remote sensing results of the mesospheric sodium layer by the OSIRIS instrument on board the ODIN satellite (Gumbel et al., 2007). We present the data extracted from Fig. 3 of the latter reference, for the period 2002-2004 and the agreement with GOMOS and Fort Collins looks reasonable. However, the validation of the OSIRIS data was performed with respect to the Fort Collins data whose climatology was also used to define the a priori profile and covariance matrix used in their optimal estimation method. This may cause a meaningless comparison when bad OSIRIS data (i.e. with large error bar measurements) could be forced to converge toward the reference climatology.

In Fig. 8, we compare the time-altitude isopleths of GOMOS Na data and the climatological Fort Collins data (19901999). The same temporal evolution is observed with a somewhat weaker amplitude for GOMOS and an earlier minimum. It should be kept in mind that the GOMOS data are interpolated at the Fort Collins latitude and that the natural observed variability is large. In the same figure, we have also plotted the annual mean of the GOMOS Na profile with its natural variability together with the mean Fort Collins data. Here again, we observe that the GOMOS peak value lies about $12 \%$ below the maximum of mean Fort Collins profile but within the associated retrieval uncertainty. This difference is also compatible with the difference between both Fort Collins climatologies of 1990-1999 and 2002-2006.
Table 1. Parameters to be used for Eq. (8). A test value is $N\left(3.5, \frac{\pi}{4}\right)=1.97 \mathrm{E} 09 \mathrm{~cm}^{-2}$.

\begin{tabular}{llrrrr}
\hline$i$ & $f_{i}$ & $a_{0}$ & $a_{1}$ & $a_{2}$ & $a_{3}$ \\
\hline 1 & $1 \mathrm{E} 09$ & 0.1282 & 1.549 & 0.1780 & 0.03511 \\
2 & 1 & 0.4017 & 0.8216 & -0.1282 & -0.2980 \\
3 & $1 \mathrm{E} 09$ & -0.2630 & 0.1121 & 0.6355 & -0.3566 \\
4 & 1 & -1.5635 & -3.0526 & 1.3802 & 1.7637 \\
\hline
\end{tabular}

\section{Climatology and interpretation}

\subsection{Na column}

After a visual and systematic inspection of the retrieved $\mathrm{Na}$ concentration profiles for all bins, $66 \%$ of them can be considered as having an acceptable or good quality (34\% do not contain enough measurements or contain outliers or show a meaningless value with respect to their inversion error). To establish a mesospheric sodium climatology, the Na column $N$ is a better estimator than the peak concentration value that might be partially anti-correlated with the peak width. We have modeled the full GOMOS data set as follows:

$$
\begin{aligned}
N(m, \varphi)\left[\mathrm{cm}^{-2}\right] & =t_{0}+t_{1} \cos \left(\frac{2 \pi}{12} m+t_{2}\right)+t_{3} \\
& \left(\varphi+\frac{\pi}{2}\right)\left(\varphi-\frac{\pi}{2}\right) \cos \left(\frac{2 \pi}{6} m+t_{4}\right) \\
t_{i \geq 1} & =f_{i}\left(a_{0}+a_{1} \varphi+a_{2} \varphi^{2}+a_{3} \varphi^{3}\right) \\
t_{0} & =3.28 \mathrm{E} 09
\end{aligned}
$$

where $m$ is the month and $\varphi$ is the geographic latitude expressed in radians. The parameters of this bivariate fit are given in Table 1.

The fit uncertainty is about $\delta N \simeq 0.81 \mathrm{E} 09 \mathrm{~cm}^{-2}$. In Fig. 9 , we present the raw GOMOS data for the Na column and the bivariate fit. The most striking feature is the semi-annual oscillation at low latitudes merging into an annual cycle in the polar regions.

It is interesting to intercompare the Na climatology with the ozone climatology derived from nighttime GOMOS retrievals (Kyrölä et al., 2010). In Fig. 10, we plotted the ozone partial column (i.e. the vertical ozone concentration profile integrated between 80 and $100 \mathrm{~km}$ ) in the region of the mesospheric ozone maximum. The same sawtooth pattern seems to emerge like a back and forth circulation between the poles, suggesting a strong mesospheric meridional circulation (see Smith, 2004 and reference therein). 

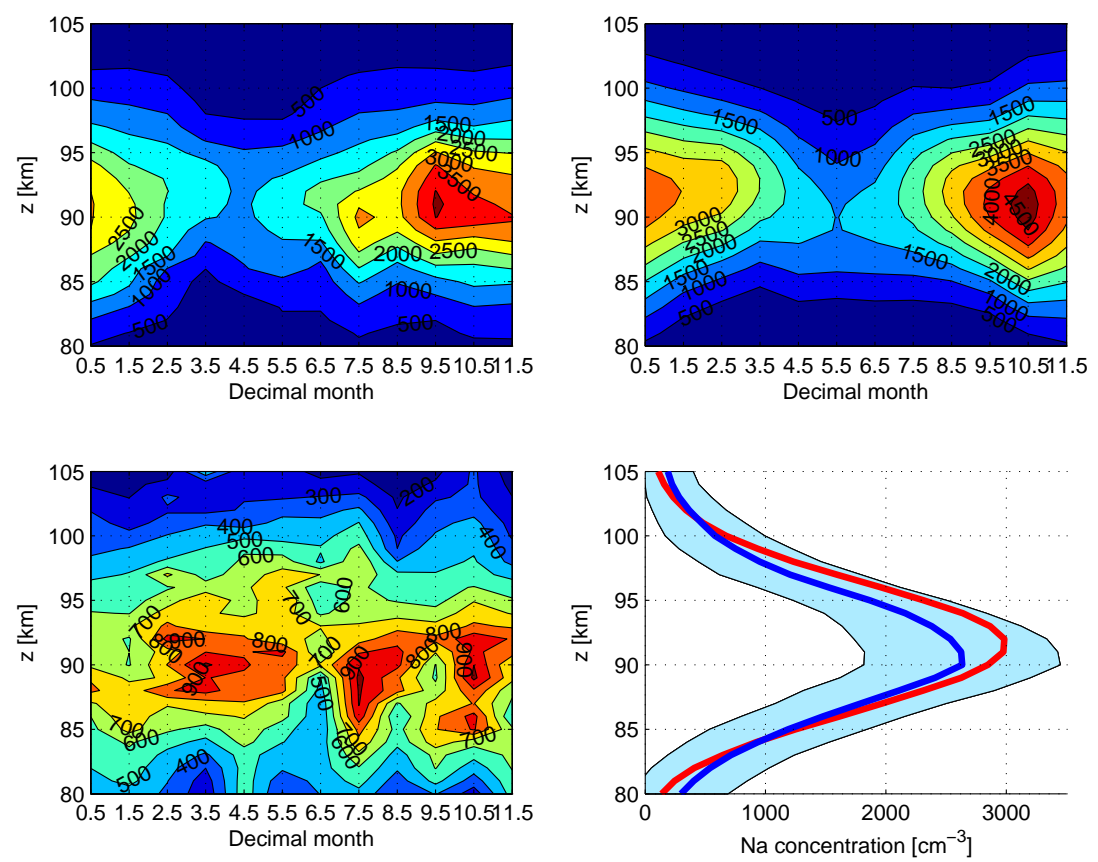

Fig. 8. Top left: time-altitude Na concentration profiles $\left(\mathrm{cm}^{-3}\right)$ measured by GOMOS in the $30^{\circ}-50^{\circ}$ latitude band. Top right: Fort Collins Na climatology (1990-1991) at $41^{\circ} \mathrm{N}$. Bottom left: GOMOS measured uncertainty. Bottom right: blue: GOMOS annual mean in the $30^{\circ}-50^{\circ}$ latitude band with the associated uncertainty envelope; red: Fort Collins annual mean profile.

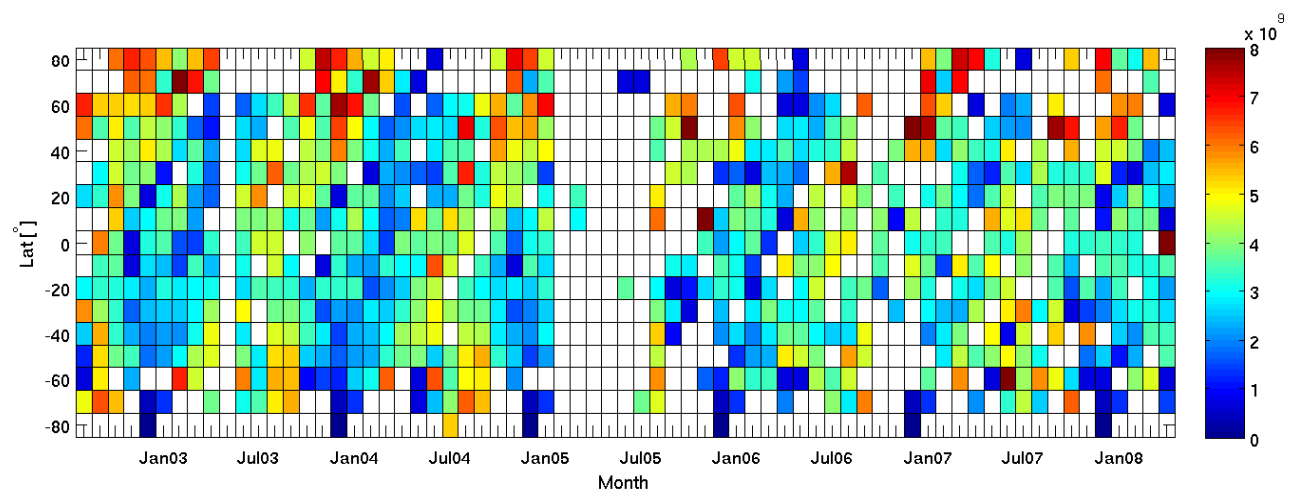

Na column $\left[\mathrm{cm}^{-2}\right]$

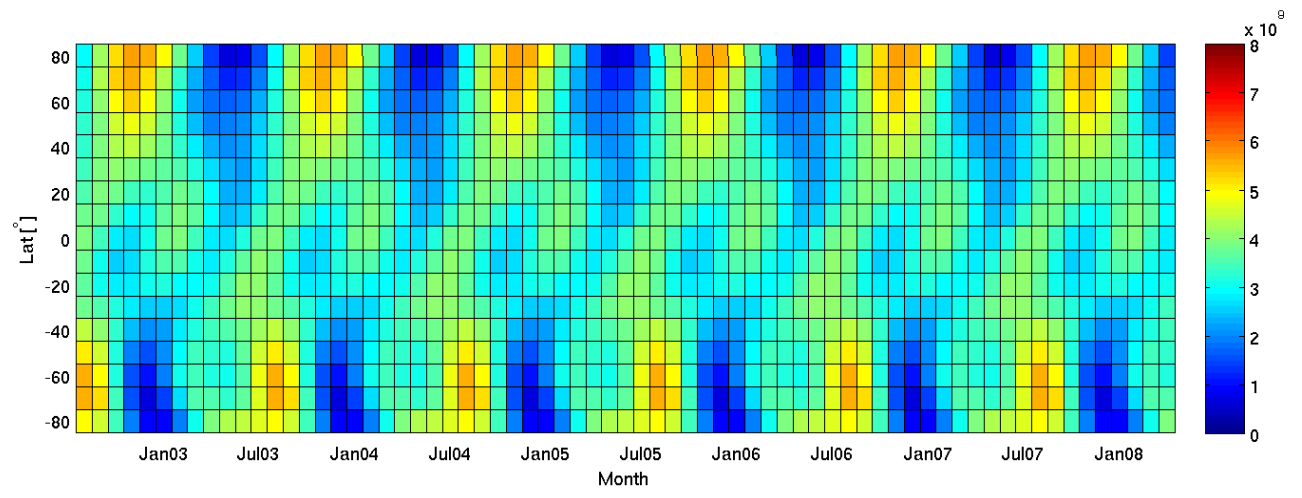

Fig. 9. Top: raw GOMOS Na columns (in units of $\mathrm{cm}^{-2}$ ) retrieved between August 2002 and June 2008. Bottom: best fit according to Eq. (8). Notice the semi-annual cycle at low latitudes and the annual cycle in the polar regions. 

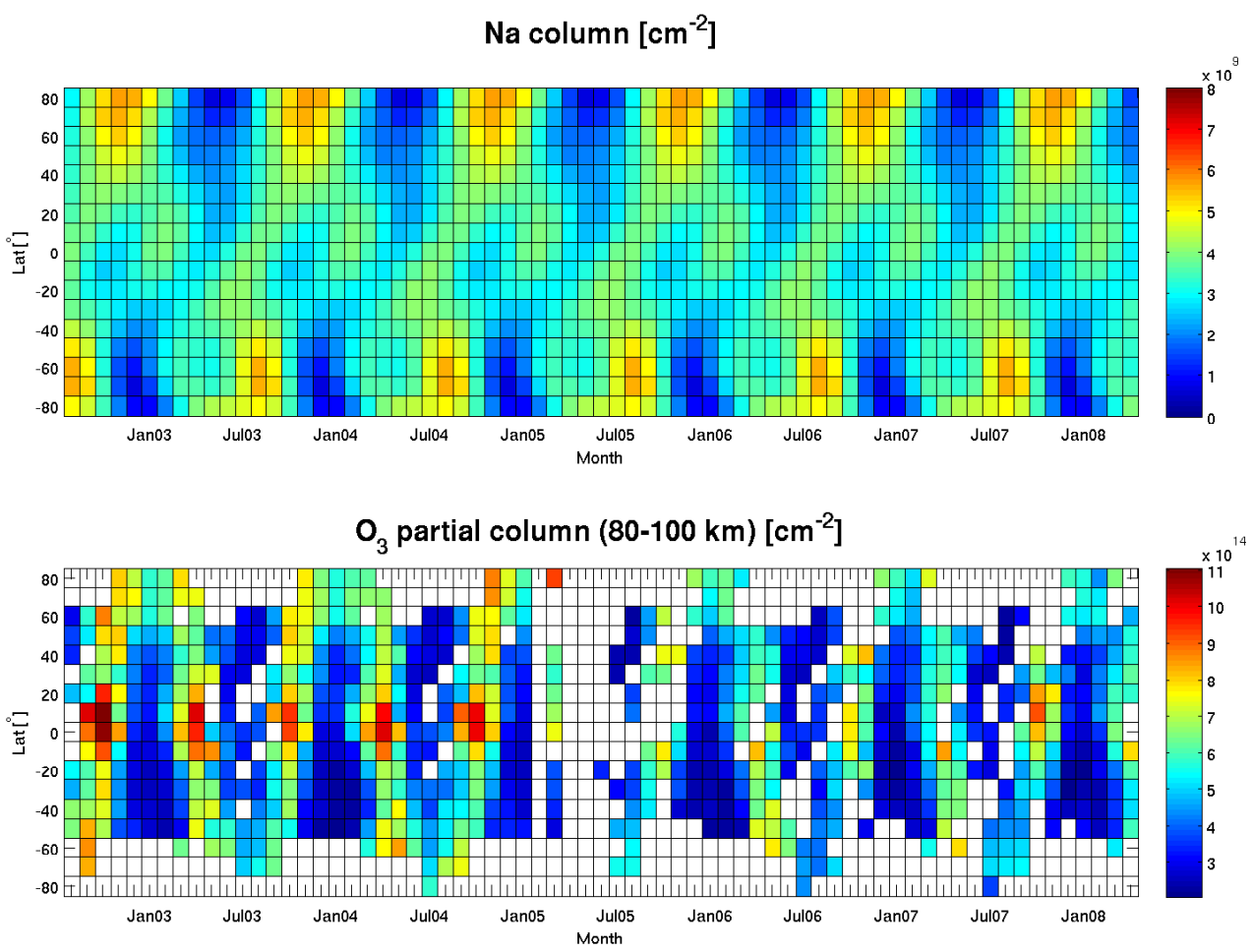

Fig. 10. Top: GOMOS sodium column climatology (as in Fig. 9). Bottom: raw GOMOS ozone partial column (between 80 and $100 \mathrm{~km}$ ). Notice the similarities between the oscillation patterns.

\subsection{Na peak altitude}

The semi-annual oscillation pattern that is very pronounced in the equatorial regions is still visible at mid-latitude. In Fig. 11, we have intercompared the altitude of the Na layer obtained by GOMOS with those obtained in the 1990-1999 Fort Collins climatology. Clearly both data sets show the same behaviour. On average, the retrieved GOMOS peak altitudes do not differ from Fort Collins values by more than $1 \mathrm{~km}$. The phase shift is not larger than 1 month, the GOMOS bin size. Also, there are periods of strong meridional gradient that nuance the accuracy of the comparison.

In Fig. 12, we present the complete climatology of the Na peak altitude. A general standard deviation of $1.6 \mathrm{~km}$ is observed. The importance of the mesospheric dynamics is again visible. Indeed, the zonal forcing by gravity wave breaking and the subsequent strong meridional circulation driven by the Coriolis force induces, through mass conservation, an important polar ascent at the summer pole and a subsidence at the winter pole (Smith, 2004). The ascent is almost adiabatic and is the cause of the very cold mesospheric temperatures around summer solstice and the related presence of PMC's. The winter subsidence is also clearly visible on the Na peak altitude with a downward shift of about $4 \mathrm{~km}$. Hereafter, we give an approximate fit for the dependence of $z_{p}$ on the latitude $\varphi$ and decimal month $m$ that only captures the annual oscillation:

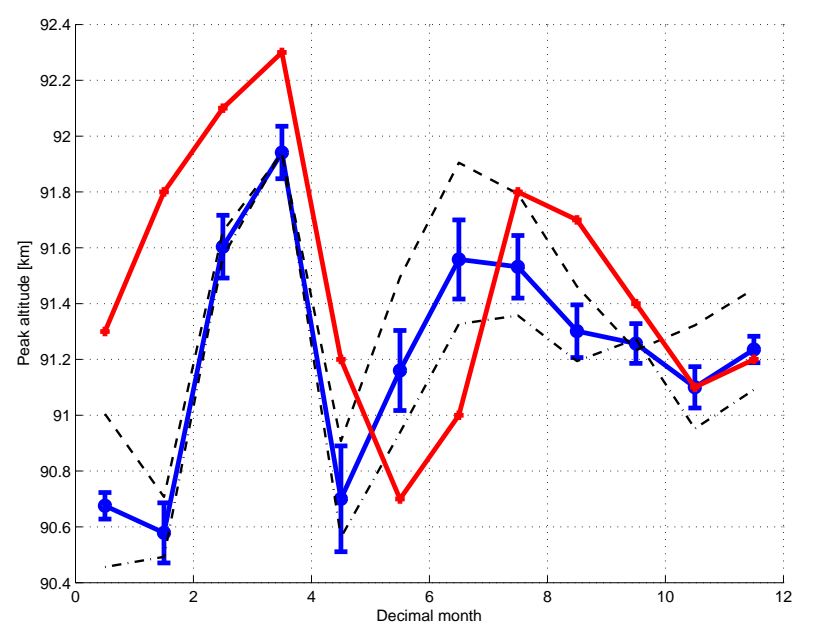

Fig. 11. Peak altitude of the Na layer. Red: Fort Collins climatology (1990-1999); black dashed line: GOMOS data in the $30^{\circ} \mathrm{N}-40^{\circ} \mathrm{N}$ bin; black dot-dashed line: GOMOS data in the $40^{\circ} \mathrm{N}-50^{\circ} \mathrm{N}$ bin; blue: GOMOS weighted interpolation at Fort Collins latitude $\left(41^{\circ} \mathrm{N}\right)$ and associated error bars.

$$
\begin{aligned}
z_{p}(m, \varphi)[\mathrm{km}]= & \left(91.98-0.7723 \varphi^{2}\right)+\left(0.1364-0.6532 \varphi^{2}\right) \\
& \cos \left(\frac{2 \pi}{12} m+1.302-0.887 \varphi\right)
\end{aligned}
$$

where $\varphi \in\left[-\frac{\pi}{2}, \frac{\pi}{2}\right]$ and $m \in[0,12]$ is the month. 

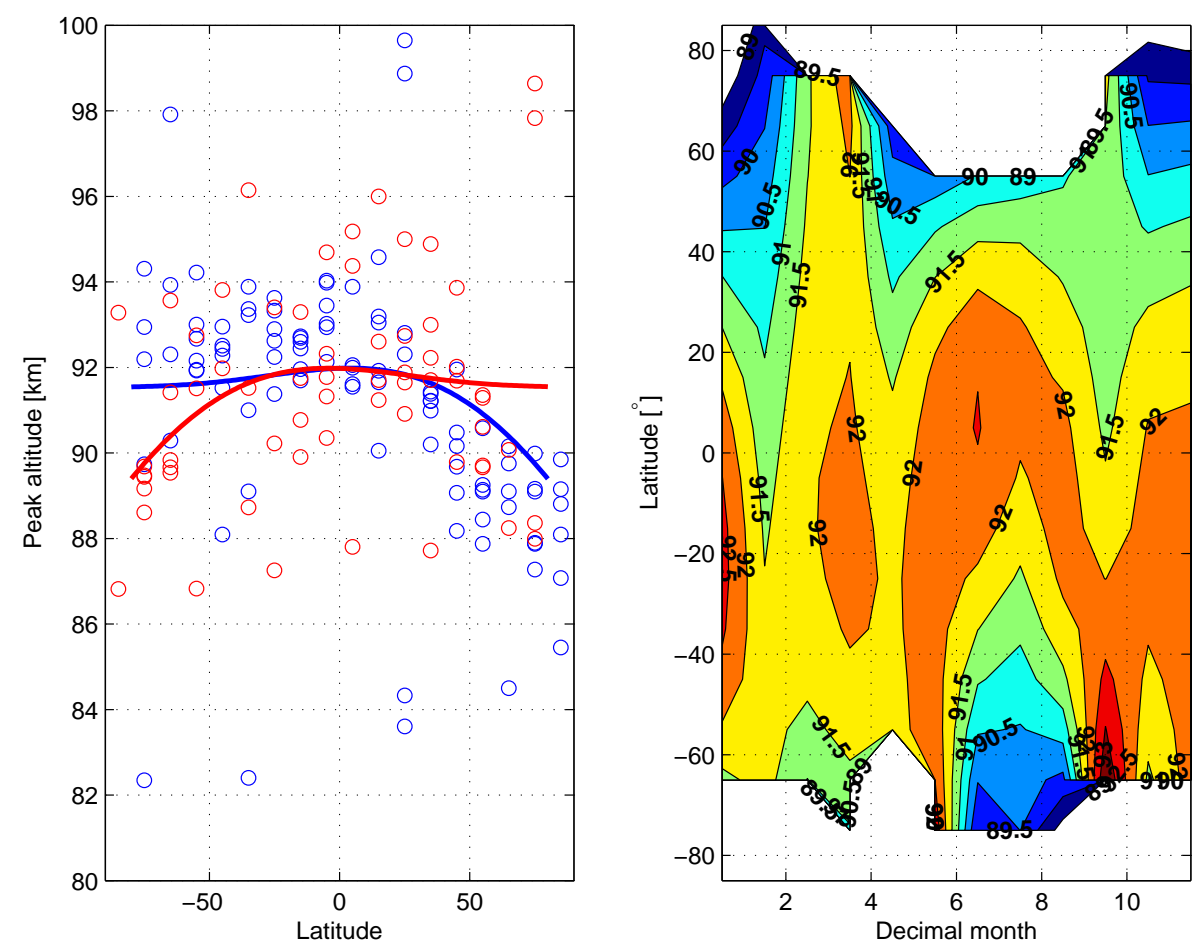

Fig. 12. Left panel: blue: retrieved peak heights (circles) in January and the approximate fit given by Eq. (9) (full line) showing the strong subsidence during polar winter; red: same data in July. Right panel: time-latitude isopleths for Na peak height.

\subsection{Na peak concentration and width}

Finally we present in Fig. 13 the maximum concentration of the mesospheric sodium layer as a function of time and latitude. A strong maximum is observed during winter in the polar regions of the northern hemisphere, with concentrations as high as 5000 sodium atoms per cubic centimeter. This maximum seems also present in the southern hemisphere but with some phase shift towards August.

When inspecting the scatter plot between retrieved peak concentrations and the full width half maximum of the $\mathrm{Na}$ profile, a partial anti-correlation was found. This is a direct consequence of sampling a narrow absorbing layer in limb viewing geometries. Most of the independent information is contained in the upper side of the layer and, when the tangent altitude decreases, the line-of-sight crosses the same layer under different angles and causes partial redundancy (see Fig. 6). In other words, it is difficult to distinguish between situations of high peak concentration/narrow layer and low peak concentration/broad layer when the signal to noise ratio of the bin is not large enough. Integrating Eq. (7), one gets for the vertical column:

$N=\int_{0}^{\infty} n(z) d z \simeq n_{0} \frac{2 \alpha \Gamma\left(\frac{1}{\epsilon}\right)}{\epsilon}=n_{0} \zeta$ where $\zeta$ can be interpreted as an effective width of the $\mathrm{Na}$ layer. But clearly, $N$ is a more robust quantity geometrically related to the slant column and the measured transmittance. Therefore for the sake of robustness, we prefer to compute the $n_{0}$ climatology as follows:

$$
\begin{aligned}
n_{0}(m, \varphi)\left[\mathrm{cm}^{-3}\right] & =\frac{N(m, \varphi)\left[\mathrm{cm}^{-2}\right]}{\bar{\zeta}} \\
\bar{\zeta} & =(12.2 e 5 \pm 3.6 e 5) \mathrm{cm}=(12.2 \pm 3.6) \mathrm{km} \\
\bar{\epsilon} & =2 \\
\bar{\alpha} & =\frac{\bar{\zeta}}{\sqrt{\pi}}=(6.9 \pm 2.0) \mathrm{km}
\end{aligned}
$$

where an equivalent Gaussian profile is imposed, leading to an effective uncertainty on $n_{0}$ of about $38 \%\left(\bar{n}_{0} \simeq 2690\right.$ atoms per cubic centimeter).

\section{Conclusions}

In this paper, we have presented the results of 7 years of GOMOS measurements of the Na mesopheric layer with a global coverage. This is the first time that such an extended data set is published and it will complete partial information obtained from ground-based measurements or more limited results obtained from space-borne instruments. 


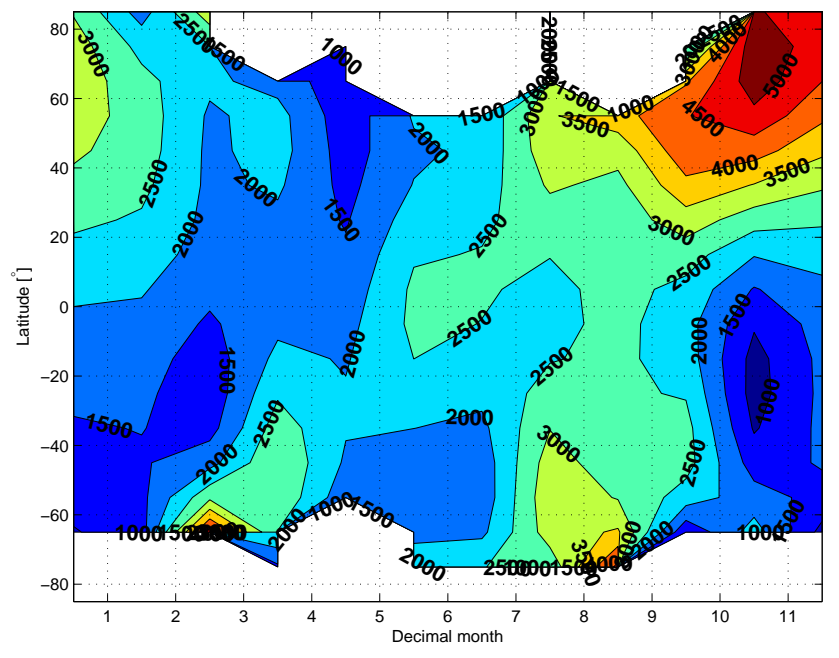

Fig. 13. Peak concentration of mesospheric sodium $\left[\right.$ atoms $/ \mathrm{cm}^{-3}$ ] as a function of time and latitude.

With respect to the preliminary results already published, we have demonstrated that $\mathrm{Na}$ slant columns produce partial saturation of the absorption lines whereas it is not the case for vertical columns, i.e. for lidar instruments. Roughly speaking, the full processing of these non-linear effects cause an enhancement of about $30 \%$ of our previous values for the $\mathrm{Na}$ column. We have demonstrated the potential effect of temperature on the retrieval even if we have limited the inversion to climatological values of temperature. However we would like to suggest a new method to measure mesospheric temperatures with a good accuracy on a global scale. This could be achieved by a solar occultation experiment (possibly also with a limb scattering geometry but with a lower SNR) in which a low resolution spectrometer (about $0.1 \mathrm{~nm}$ ) is measuring the sodium absorption doublet $\mathrm{D}_{2} / \mathrm{D}_{1}$ around $589 \mathrm{~nm}$. Although the very narrow absorption lines are mainly broadened by the instrument line spread function and become small absorption features in the transmittance spectra, the measurement of the apparent optical thickness by differential absorption spectroscopy and of the $\mathrm{D}_{2} / \mathrm{D}_{1}$ ratio allows for the simultaneous retrieval of $\mathrm{Na}$ concentration and mesospheric temperature.

The principal result of this climatology is the discovery of a double pattern for the mesospheric sodium latitudinal and temporal distribution, i.e. a semi-annual equatorial oscillation that merges into an annual polar oscillation. This was unreported so far in the literature and this pattern turns out to be quite similar to the ozone distribution measured by GOMOS. We have also shown the important subsidence observed during polar winter that demonstrates the accepted view of the general mesospheric circulation driven by the seasonal gravity wave break-up. Although comprehensive chemical models of the sodium mesospheric layer already exist, they only refer to the impact of temperature on the involved reaction rates for $\mathrm{Na}$ sources and sinks whereas this paper demonstrates the necessity of using a realistic transport model capable of explaining the semi-annual equatorial oscillation. In particular, it has been suggested that the polar mesospheric clouds could be responsible for the strong decrease of the $\mathrm{Na}$ abundance during polar summer but this hypothesis still has to be validated against dynamical effects in the mesosphere. The strong sodium decrease in the polar summer mesosphere has been suggested to been a combination of the effect of PMC and cold temperatures (Fan et al., 2007).

We have found a generally fair agreement in the validation of our results with lidar and limb viewing instruments. However, we confirm that the sodium natural variability is high $(30-50 \%)$ and this was already reported from ground-based climatologies. For this reason, we have approximated the $\mathrm{Na}$ vertical column with a robust fit capable of reproducing the annual and semi-annual phases and amplitudes. The winter subsidence of the Na peak was modelled in the same way. Finally, we described the sodium concentration and profile width from the total column fit by assuming an equivalent Gaussian profile for all bins.

In future work we will feed a general CTM model with our data. Also, we will investigate more accurately the shape of the $\mathrm{Na}$ concentration profile but only for the best available bins. We are also planning to cross validate the GOMOS transmittance data with $\mathrm{Na}$ airglow data that can possibly be retrieved from the upper and lower bands of the GOMOS sensor. Finally, we will process the full GOMOS data set in order to discover signatures of other mesospheric metallic layers.

Acknowledgements. This study was funded by the PRODEX 9 contract SECPEA under the authority of the Belgian Space Science Office (BELSPO).

Edited by: D. Murtagh

\section{References}

Arnold, K. S. and She, C. Y.: Metal fluorescence lidar (light detection and ranging) and the middle atmosphere, Contemp. Phys., 44(1), 35-49, 2003,

Bertaux, J. L., Hauchecorne, A., Dalaudier, F., Cot, C., Kyrölä, E., Fussen, D., Tamminen, J., Leppelmeier, G. W., Sofieva, V., Hassinen, S., dAndon, O. F., Barrot, G., Mangin, A., Theodore, B., Guirlet, M., Korablev, O., Snoeij, P., Koopman, R., and Fraisse, R.: First results on GOMOS/Envisat, Adv. Space Res., 33, 10291035, 2004.

Chamberlain, J. W.: Physics of the Aurora and Airglow, Academic Press, New York and London, 1961.

Fan, Z. Y., Plane, J. M. C., Gumbel, J., Stegman, J., and Llewellyn, E. J.: Satellite measurements of the global mesospheric sodium layer, Atmos. Chem. Phys., 7, 4107-4115, doi:10.5194/acp-74107-2007, 2007.

Fricke, K. H. and von Zahn, U.: Mesopause temperatures derived from probing the hyperfine structure of the $\mathrm{D}_{2}$ resonance line of sodium by lidar, J. Atmos. Terr. Phys., 47(5), 499-512, 1985. 
Fussen, D., Vanhellemont, F., Bingen, C., Kyrola, E., Tamminen, J., Sofieva, V., Hassinen, S., Seppala, A., Verronen, P., Bertaux, J. L., Hauchecorne, A., Dalaudier, F., Renard, J. B., Fraisse, R., d'Andon, O. F., Barrot, G., Mangin, A., Theodore, B., Guirlet, M., Koopman, R., Snoeij, P., and Saavedra, L.: Global measurement of the mesospheric sodium layer by the star occultation instrument GOMOS, Geophys. Res. Lett., 31, L24110, doi:10.1029/2004GL021618, 2004.

Gardner, C. S., Plane, J. M. C., Pan, W., Vondrak, T., Murray, B. J., and Chu, X.: Seasonal variations of the $\mathrm{Na}$ and Fe layers at the South Pole and their implications for the chemistry and general circulation of the polar mesosphere, J. Geophys. Res., 110, D10302, doi:10310.11029/12004JD005670, 2005.

Gumbel, J., Fan, Z. Y., Waldemarsson, T., Stegman, J., Witt, G., Llewellyn, E. J., She, C. Y., and Plane, J. M. C.: Retrieval of global mesospheric sodium densities from the Odin satellite, Geophys. Res. Lett., 34, L04813, doi:10.1029/2006GL028687, 2007.

Kyrölä, E., Tamminen, J., Sofieva, V., Bertaux, J. L., Hauchecorne, A., Dalaudier, F., Fussen, D., Vanhellemont, F., Fanton d'Andon, O., Barrot, G., Guirlet, M., Fehr, T., and Saavedra de Miguel, L.: GOMOS $\mathrm{O}_{3}, \mathrm{NO}_{2}$, and $\mathrm{NO}_{3}$ observations in 2002-2008, Atmos. Chem. Phys., 10, 7723-7738, doi:10.5194/acp-10-77232010, 2010.
Mégie, G. and Blamont, J. E.: Laser sounding of atmospheric sodium interpretation in terms of global atmospheric parameters, Planet. Space Sci., 25, 1093-1109, 1977.

Plane, J. M. C.: Atmospheric chemistry of meteoric metals, Chem. Rev., 103, 4963-4984, 2003.

Plane, J. M. C., Murray, B. J., Chu, X., and Gardner, C. S.:Removal of Meteoric Iron on Polar Mesospheric Clouds, Science, 304, 426-428, doi:10.1126/science.1093236, 2004.

She, C. Y., Chen, S. S., Hu, Z. L., Sherman, J., Vance, J. D., Vasoli, V., White, M. A., Yu, J. R., and Krueger, D. A.: Eight-year climatology of nocturnal temperature and sodium density in the mesopause region (80 to $105 \mathrm{~km})$ over Fort Collins, $\mathrm{CO}\left(41^{\circ} \mathrm{N}\right.$, $105^{\circ}$ W), Geophys. Res. Lett., 27, 3289-3292, 2000.

Smith, A. K.: Physics and chemistry of the mesopause region, J. Atmos. Sol.-Terr. Phy., 66, 839-857, 2004.

Steck, D. A.: Sodium D Line Data, Los Alamos National Laboratory Technical Report LA-UR-03-8639, revision 1.6, available at: http://steck.us/alkalidata, 2003. 